low-dose glucocorticosteroids did not influence altered body composition during the first year of eRA therapy.

References:

[1] Book C, Karlsson MK, Nilsson JA et al. Changes in body composition after 2 years with rheumatoid arthritis. Scandinavian Journal of Rheumatology 2011(40:2); 95-100.

[2] Schtz Y, Kyle UUG, Pichard C. Fat-free mass index and fat mass index percentiles in Caucasians aged 18-98 y. International Journal of Obesity 2002(26);953-960.

[3] Engvall IL, Brisman K, Hafström I et al. Treatment with low-dose prednisolone is associated with altered body composition but no difference in bone mineral density in rheumatoid atrhritis patients: a controlled cross-sectional study. Scandinavian Journal of Rheumatology 2010(40:3)161-168.

Disclosure of Interest: None declared

DOI: 10.1136/annrheumdis-2017-eular.3124

\section{AB0298 ANTIBODIES TO CYCLIC CITRULLINATED PEPTIDE AND MODIFIED CITRULLINATED VIMENTIN: A ROLE IN RHEUMATOID ARTHRITIS ASSOCIATED WITH AUTOIMMUNE THYROIDITIS}

A. Dvorovkin ${ }^{1}$, V. Odin ${ }^{1}$, O. Inamova ${ }^{2}$, V. Tyrenko ${ }^{1}$, M. Toporkov ${ }^{1}$. ${ }^{1}$ Faculty therapy, Military Medical Academy Named After S.M. Kirov; ${ }^{2}$ Clinical Rheumatic Hospital No. 25, St. Petersburg, Russian Federation

Background: Specific antibodies, including antibodies to cyclic citrullinated peptide (ACCP) and modified citrullinated vimentin (AMCV) are markers of severe course of rheumatoid arthritis (RA). At the same time, rheumatoid arthritis often associated with autoimmune thyroiditis (Hashimoto's thyroiditis (HT)).

Objectives: Evaluate the role of antibodies to ACCP and AMCV on the clinical and laboratory features of rheumatoid arthritis in association with autoimmune thyroiditis.

Methods: The study included two groups of patients. The first group of patients included 16 patients ( 14 men and 2 women, mean age $-62.37 \pm 2.12$ years) with $\mathrm{RA}$ in combination with HT and detection in the blood only ACCP (group 1). The second group also included 16 patients (14 women and 2 men, mean age - 52.31 \pm 4.94 years) with RA in combination with HT and detection of ACCP and $A M C V$ in the blood (group 2). In the first group of patients 10 patients had euthyreose, from 5 - hypothyroidism, compensated intake of $L$ - thyroxine, 1 patient - thyrotoxicosis underway medikal euthyreose. In the second group of patients was observed in 14 patients euthyreose, from 2 - hypothyroidism, compensated reception L-thyroxine.

Results: Both groups of patients differed on the following parameters studied: erosion detected in $68 \%$ in group 1 and $50 \%$ in group $2(\mathrm{p}<0,05)$, in the first group of patients predominated $(62 \%)$ the high degree of activity of RA by DAS-28, in while in group 2 - the average $(56 \%, p<0,05)$.

By using correlation analysis Spearman correlation relationships among the studied attracted attention significant $(R=0,62, p<0,05)$ relationship between erosions and detection in the blood of antibodies to ACCP in the second group of patients (a combination of RA and HT and identifying in blood ACCP and AMCV), which was repeatedly weakened and unreliable in group 1 (combination of RA and HT and only detect of ACCP) in the blood.

Conclusions: Second group patients (a combination of RA with HT and detection in blood ACCP and AMCV) are closer correlations with indicators of joint destruction than group 1 patients, that in the future may use as a prognostic marker of a more severe course of RA in combination with $\mathrm{HT}$.

Disclosure of Interest: None declared

DOI: 10.1136/annrheumdis-2017-eular.4172

\section{AB0299 ATLANTOAXIAL SUBLUXATION AS A PROBLEM IN PATIENTS WITH RHEUMATOID ARTHRITIS}

S. Misevska Percinkova ${ }^{1}$, A.A. Kuchi ${ }^{2}$. ${ }^{1}$ Dept. for Inflamatory Rheumatic Disease, University Rheumatology Clinic; ${ }^{2}$ Dept. for Internal Medicine, PHO City Health Centre Skopje 1, Skopje, Macedonia, The Former Yugoslav Republic Of

Background: Atlantoaxial subluxation (AAS) is important and potentially life threatening complication of Rheumatoid arthritis (RA). It is defined when the space between odontoid process from $\mathrm{C} 2$ and arch of the atlas exceeds more than $3 \mathrm{~mm}$. Instability in atlantoaxial joint may result with numerous neurological symptoms, compression of spinal cord and ultimately quadriparesis or quadriplegia.

Objectives: Aim of the study was to determine the frequency and the characteristics of atlantoaxial instability among our patients with RA and its dependence on the nature of the disease.

Methods: 92 outpatients from University Rheumatology Clinic in Skopje, with classical RA (ACR criteria 1988) were examined for the AAS. In all cases were analysed the duration of the disease, haematological and serological tests, disease activity (DAS 28), visual analogue scale (VAS) for the degree of articular pain and verbal rating scale (VRS).for cervical-occipital pain. All patients underwent native and functional $x$-ray, CT scan and MRI of cervical spine. A complete neurological examination was obtained, with SEP of the $n$. medianus et $n$. tibialis. Results: Atlantoaxial instability, with expressed cervical-occipital symptomatology, occurred in 54 from $92(58,69 \%)$ patients with RA. AAS appeared significantly more often in patients with longer duration of the disease $(p<0,0001)$, in cases with significant cervical-occipital pain (VRS $p<0,0001$ ), with stronger joint pains (VAS), with higher values of SR $(p=0,002), \operatorname{CRP}(p=0,023), \operatorname{RF}(p=0,000005)$, anti CCP $(p=0,00003)$, and DAS $28(p<0,0001)$. Anaemia and thrombocytosis $(p=0,0008)$ appeared significantly more in cases with AAS. Anterior AAS, (mostly combined with other types) was the most frequent type, presented in 41 participants $(75,92 \%)$. In one case posterior AAS was detected, what is very rare finding. Positive SEP was significantly higher in the group with AAS

Conclusions: AAS is serious extra-articular manifestation of RA. Cervical subluxation may be a general anesthetic risk and risk for a neck injury. Routine cervical radiographs with the head in flexed position should be recommended in need of general anaesthesia and in situations with risk for a neck injury.

Acknowledgements: Rheumatoid arthritis, atlantoaxial subluxation.

Disclosure of Interest: None declared

DOI: 10.1136/annrheumdis-2017-eular.5033

\section{AB0300 ASSOCIATION OF VITAMIN D STATUS WITH RHEUMATOID ARTHRITIS DISEASE ACTIVITY AND UV INDEX}

C. Lopes $^{1}$, J.L. Gomes ${ }^{1,2}$, T. Costa ${ }^{1}$, M. Mateus ${ }^{1}$, F. Pimentel-Santos ${ }^{1,2}$, J.C. Branco ${ }^{1,2} .{ }^{1}$ Rheumatology Department, Hospital de Egas Moniz / CHLO; ${ }^{2}$ CEDOC, NOVA Medical School / Faculdade de Ciências Médicas - NOVA University of Lisbon, Lisbon, Portugal

Background: Lower serum vitamin D levels have been shown to be associated with various autoimmune disorders, including Rheumatoid Arthritis (RA). Vitamin $\mathrm{D}$ deficiency is common in RA patients, despite profiting from a sunny country. Objectives: The aim of the study is to evaluate (1) - the association between vitamin $D$ serum levels and disease activity in patients with $R A ;(2)$ - seasonal distribution of vitamin D levels.

Methods: Patients fulfilling the 2010 EULAR/ACR Rheumatoid Arthritis Classification Criteria, which had serum vitamin D [25(OH)D3] levels measured between January 2013 and December of 2016 were included. Demographic data, disease activity scores, including DAS283v-CRP and DAS283v-ESR, vitamin D supplementation with cholecalciferol and other therapeutic approaches were recorded. Vitamin D insufficiency was considered between $25-75 \mathrm{nmol} / \mathrm{L}$ and deficiency if $<25 \mathrm{nmol} / \mathrm{L}$. According to the national agency for the study of sea and atmosphere, UV Index levels were grouped into low UV Index 3-6 (October to April) and high UV Index 9-10 (May to September). Correlation between variables was analyzed using Spearman's rho.

Results: A sample composed by 95 patients, 79 females (83.16\%), with an average age (SD) of 68.57 (11.92) years within 40-88 years range were included. Average disease duration was $13.46(11.41)$ years. The average age at diagnosis was 57.10 (14.25) years. The average vitamin D levels were 78.13 (60.98) $\mathrm{nmol} / \mathrm{L}$ in a range between $20-400 \mathrm{nmol} / \mathrm{L}$. Vitamin D levels were not significantly different in male $v s$. females patients. The prevalence of vitamin $D$ insufficiency and deficiency was $53.68 \%$ and $8.42 \%$ respectively, despite $57.89 \%$ of the patients taking supplementation (average 6141 (4800) UI/week). The univariable analysis showed that albeit vitamin $\mathrm{D}$ levels presented a negative poor correlation with DAS283v-CRP (rho $=-0.348$, p-value $<0.001)$ and DAS283v-ESR (rho $=-0.271$, $p$-value $<0.01$ ), there was a direct reduction in dispersion of the vitamin $D$ values for increasing values of DAS283v-CRP and ESR. It was observed that vitamin D levels increase with patient age and decrease with disease duration. Sazonality and supplementation didn't affect vitamin D levels in our population.

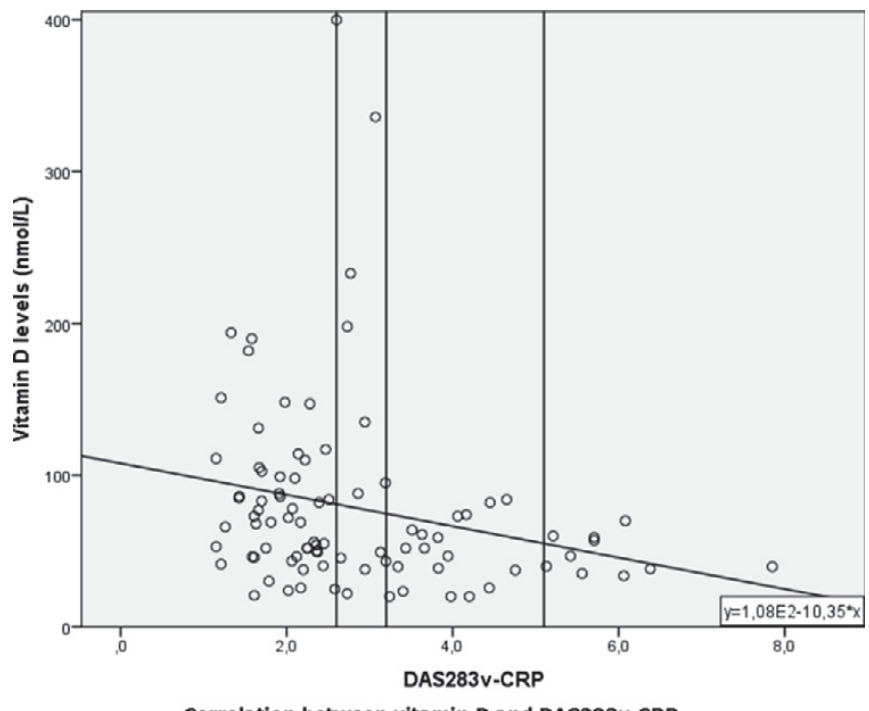

Conclusions: Vitamin D insufficiency/deficiency was frequent among RA patients $(62.1 \%)$, independently of seasonality or supplementation. An interesting pattern 